\title{
ENQUADRAMENTO E RELATO: IMAGEM E MOVIMENTO NO FILME CENTRAL DO BRASIL
}

\author{
Pedro Plaza Pinto ${ }^{1}$
}

Só via os longes de um quadro. Chatos mapas. O absurdo ar. O céu de se abismar. E indagava o chão. Rastreava. João Guimarães Rosa

\section{Apresentação: fluxo do relato e refluxo pela imagem}

Quando estudamos filmes de caráter eminentemente narrativo, é necessário articular de modo intrínseco a instância das imagens e a instância da narrativa. Tal necessidade advém na medida em que o material traz, no seu discurso, a intermitente apresentação de imagens que sustentam ou quebram o ritmo ou a temporalidade do relato e sugerem relações simbólicas ou simplesmente significativas. Esta intermitência ou a simples emolduração do relato caracteriza variados ramos da estética cinematográfica em diferentes propostas de construção, mas é definidora da própria natureza do contar cinematográfico típico do modelo da decupagem clássica. Desde D. W. Griffith, paradigmático diretor da nascente indústria hollywoodiana, é possível apontar, no interior da cena e em pleno fluxo narrativo, a construção de quadros através de enquadramentos que remetem a determinados aspectos da representação pastoral e da lógica de definição das personagens segundo o melodrama de matriz industrial.

Tendência eminente no teatro de tradição cristã, herança da Idade Média, o "quadro" (tableau) é um elemento a mais dentro da estratégia pedagógica de orientação do espectador na narrativa do filme de decupagem clássica². Há, aqui, o princípio mais amplo da necessidade de apagamento das contradições e de explicitação das normas, desvios de conduta, caráter e dilemas das personagens que orienta certos procedimentos que estão presentes na estética do cinema realista-melodramádico do filme Central do Brasil (Walter Salles, 1996). O filme narra a aventura transformadora do caráter de Dora (Fernanda Montenegro), que é levada a cumprir um trajeto típico de filmes de estrada (road movies) ao acompanhar um garoto à casa do pai. Após a apresentação do seu mau caráter, a senhora resolve desfazer a negociação com uma quadrilha de

\footnotetext{
${ }^{1}$ Universidade Federal do Paraná, Brasil.

2 Ismail Xavier (2003: 112 e 113) ressalta a importância das Morality Plays na genealogia do gênero melodramático desenvolvido pelo cineasta americano do começo do século XX, D.W. Griffith, a exemplo do filme The White rose (1921).
} 
aliciadores e devolver o menino ao seu núcleo familiar. No melodrama de reintegração moral está implicada a reorganização de uma família destroçada.

A pergunta de fundo que orientou a análise proposta por este texto é: em que elementos da sua estética relativamente múltipla podemos apontar a permanência, o eco de Griffith, para além da construção do fluxo do relato estável e contínuo próprio do modelo clássico? Na medida em que o mundo da narrativa de Central do Brasil traz em seu bojo a alegoria da esperança e da busca quase mítica do pertencimento, em seu contínuo desenrolar rumo ao "mais próprio", faz-se mister estudar como o filme pontua este caminho com: 1) imagens que constituem quadros; 2) quadros que constituem distâncias, ou como preferimos chamar, "os longes do quadro"; 3) contrapontos entre quadros que orientam a apreensão do espectador sobre como entender situações e personagens.

Evidentemente, trata-se de um estudo que se detém sobre o cinema narrativo em sua interseção com o estudo das imagens. Aferra-se também na defesa da análise fílmica como procedimento fundamental para desvelar elementos formais que são coerentes apenas na aparência. O exemplo mais importante está na relativização da verificação óbvia de que Central do Brasil expõe um relato cujo efeito principal é estabelecer um horizonte, um caminho sem fim. Ora, trata-se de um movimento que só ganha corpo na medida em que os elementos informes dos personagens e de suas situações - estamos a tratar de um típico melodrama - são orientados justamente segundo uma dialética entre movimento e repouso, dentro da qual o relato simboliza sobre personagens, episódios e expectativas.

O que dizer da cena final, onde é justamente entre repouso e movimento que se distingue o desenlace próprio de cada uma das personagens principais? Dora (Fernanda Montenegro) permanece no fluxo em direção ao longe do quadro e traz ao espectador o tom de balanço emocionado, enquanto Josué (Vinícius de Oliveira) observa parado de longe da estrada e, em seguida, fixa a sua curta experiência olhando a fotografia do monóculo. O menino encontrou um lugar de acolhimento junto aos irmãos e seu choro sinaliza o afeto reencontrado pela lembrança da mulher que teve o seu caráter corrigido. A senhora elabora os pontos nodais de sua experiência de ressentimento contra o pai, também reencontrando afeto onde não esperava, tendo sido redimida ao ser guiada pelo "anjo" Josué.

Neste artigo, está em questão a maneira como o filme molda a sua fábula moral com o apoio de suspensões do fluxo do relato, utilizando-se de enquadramentos que 
distinguem quadros ${ }^{3}$ e de montagens que distinguem identidades. Um exemplo concreto que podemos trazer, a título de introdução, está na construção do imaginário da criança do que seria o seu lugar mais próprio, em duas sequências. A primeira se passa na chegada de Josué à casa de Dora, quando o menino examina desenhos e ilustrações na parede da casa da mulher que intenta vendê-lo a uma quadrilha. Ele vê uma virgem acolhedora (já estamos lidando com a memória simbólica da mãe?) e percebe uma casinha pintada em um quadro de louça. Uma casinha também bastante típica do viver interiorano ou sertanejo, agora realizado, aparece na sequência da falsa resolução do filme, quando Dora e Josué chegam a Bom Jesus do Norte e visitam a antiga casa de Jesus, pai de Josué. O movimento da câmera suspensa numa grua enquadra, de cima, o lugar, e estabelece a similitude necessária para incitar a expectativa de que aquele sítio seja o espaço imaginado da criança e a solução aguardada pelo espectador. A música com volume crescente e o gesto da corrida da criança incitam ainda mais o jogo de expectativas. No decorrer da cena, a verdade é revelada e o mal entendido é desfeito. Há outra família residindo no local. A narrativa retoma o seu fluxo de incessante procura e o filme continua.

Com a sua história centrada num projeto de "re-sensibilização" em contexto onde grassava o paradigma do encontro inesperado e do ressentimento ${ }^{4}$, Central do Brasil foi objeto de vastíssima quantidade de escritos. Apenas a título de uma indicação de abordagens que nos interessaram: Moutinho (2000) considera o filme uma redefinição da solidariedade e individualidade no sentido de uma solidariedade contemporânea; Hermanns (1996) destaca a viagem exterior e interior, concreta e existencial que estariam presentes no relato; Vasconcelos (1999) considera o filme o melhor representante de uma estética ex-FHC por valorizar a moeda na mão do menino justamente na época da falsa estabilidade econômica; Canevacci (1998) vincula o filme a uma conservadora busca televisiva de uma identidade simbólica pai-Estado; Oliveira (1996) aponta uma redenção proposta pela fábula ao identificar uma estética da comunicabilidade das missivas desencontradas como possibilidade de reaproximação com o público na cinematografia brasileira contemporânea.

A nossa abordagem pressupõe esta discussão sobre o cariz do relato, examinado

3 Foi fundamental, para este estudo, a conceituação das noções de quadro e de enquadramento do livro Olho interminável [cinema e pintura], de Jacques Aumont (2004: 37-43).

4 Conferir o texto de Ismail Xavier (2001), Figuras do ressentimento no cinema brasileiro dos anos 90 , em que o crítico indica a persistência da figuração do encontro inesperado e do ressentimento no cinema brasileiro do final do século XX. Ver também a entrevista para a Revista Praga, O Cinema brasileiro dos anos 90 (Xavier, 2000). 
aqui a partir da interveniência do quadro. Este estudo trata, portanto, da relação entre imagem e narração no filme Central do Brasil a partir de apontamentos sobre paradigmas tradicionais do melodrama e de inovações acerca da construção das distâncias dentro do quadro. Alguns dos procedimentos básicos de montagem e construção do quadro compõem a narrativa e elaboram um ordenamento típico da decupagem clássica. Suspensões momentâneas no andamento do relato destilam a psicologia dos personagens, suas normas e desvios de conduta.

\section{Campo, olhar e enquadramento}

A ficção é construída, para o espectador, na ordem narrativa, através do seu ato produtor, a narração. Entretanto, tal ordem não é simplesmente a sequência linear, mas composta de uma rede de muitos ramos intervenientes: vaticínios, indícios, vestígios, correspondências, recordações, saltos, deslocamentos. A narrativa fílmica é finita e se estabelece (se organiza) numa lógica própria (coerência), articulando uma história (legível) através de uma narração. Afinal, "o texto narrativo é um discurso fechado, porque comporta inevitavelmente um início e um fim, porque é materialmente limitado" (Aumont et al, 1995: 108).

A narração é o próprio ato de contar a história, por extensão, a situação de ficção tomada no desenrolar da história. Inscreve-se na narrativa, ou seja, só pode ser analisada na materialidade das imagens e sons, como filme legível. A narração é a ligação entre enunciação e enunciado, entre narrativo e narrado, estabelecendo implicação entre os jogos da narrativa e a história contada, a situação. Esses jogos são regulados por ordens de sentido, a história sendo contada de uma certa forma, segundo certos critérios coerentemente estabelecidos numa organização da representação.

Em relação à Central do Brasil, não se trata de uma narrativa realista comum, mas de um melodrama que possui um sentido geral alegórico.

[...] alegórico desde seu título e em toda a sua parábola de redenção moral, o contraponto a este espírito de vingança contra o mundo se constrói no motivo do encontro inesperado, agora entre uma velha dama indigna e uma figura de inocência. $O$ roteiro se assenta numa polarização entre bem e mal sem a qual a reviravolta final não teria o mesmo efeito. (Xavier, 2001: 93).

É justamente a figura de inocência que localizamos no centro da montagem, entre 
quadros significativos, de imagens que se relacionam para criar símbolos que garantem esteio psicológico ao imaginário da criança. É uma construção de apoio às lições morais, temperadas pelo ingrediente de contenção e resolução de expectativas nos episódios.

$\mathrm{Na}$ apresentação deste texto, mostramos um tipo de articulação da montagem entre momentos disjuntos: a casinha pintada e emoldurada pelo material de louça, da parede da casa de Dora, ganha dimensão real com o enquadramento superior do movimento ascendente da grua na sequência da chegada a Bom Jesus do Norte. A casinha imaginada enraiza e justifica o desejo de Josué, além de promover a expectativa da resolução do conflito para o espectador.

Examinemos o seguimento da mesma sequência e a sua intensificação de expectativas quando o menino chega próximo da entrada da casa. A câmera já abandonou o ângulo superior e a escala geral. A música se transforma quando o filme nos dá a ver que Josué percebe a presença de outro infante do lado interior da cerca de arame farpado que está colorida com roupas secando ao vento. Ambos trocam olhares e logo se estabelece para além do procedimento básico do campo/contracampo, um jogo de espelhos. Os meninos se movimentam e a câmera também se movimenta, a montagem intercambiando os ângulos do campo e contracampo. O movimento e o pingue-pongue típico da decupagem clássica conduz a dinâmica de identificação, trabalhando com a criação do duplo: há a criança sem casa, há o menino que ali reside. Entre eles, o arame farpado e as roupas ao vento. O espectador se pergunta: trata-se de outra criança filha de Jesus, pai de Josué?

Este efeito suspensivo promove o encontro definitivo entre cinema e narratividade pelo uso da imagem, nos termos da decupagem clássica. Efetiva a elaboração de uma intriga "apimentada" pelo suspense. Para efeito de comparação, é importante lembrar que a tônica inicial do suspense em Griffith é calcada na ameaça da família, que encontra sua expressão estilística na oposição entre os espaços internos e externos, demandando uma solução dramática nas portas e janelas com a montagem em continuidade. Em Central do Brasil, o uso das portas e janelas como expressões estilísticas também reverbera os ecos do princípio do século passado, da criação do modelo narrativo-dramático. A mudança de espaço solicita o movimento constante e as mudanças espaço-temporais são amenizadas com o uso de sonoridade

O exemplo mais eloquente da utilização de uma porta no filme está na emolduração que acontece logo após o desvelamento da pequena confusão da chegada 
de Dora e Josué à casa da família de Jessé. É a cena que se segue à criação da identidade entre Josué e o menino do outro lado da cerca. Assim que Jessé compreende que Dora na verdade procura outro homem, vemos Josué abaixar a cabeça e se deslocar para a saída da pequena sala. Podemos dizer que é o momento de maior busca da criação de um tableau pelo filme, uma vez que a câmera se utiliza do recurso da sobreemolduração do quadro com o portal da sala: Josué se vira, sai lentamente, e a câmera se dedica, por longos segundos pontuados pela música melancólica, com sons de cordas friccionadas, a observar o menino de costas, já do lado de fora, solitário e caminhando para longe, ainda de cabeça baixa. $\mathrm{O}$ que aconteceu com os personagens do lado de dentro da sala? A narrativa tampouco se preocupa com o ritmo do relato e abandona totalmente o diálogo entre Dora e Jessé. Da cena, resta o quadro bastante significativo do menino solitário, afastando-se lentamente, de costas para a câmera. Elabora-se uma emolduração com a porta que vai além da simples enunciação narrativa de continuidade, construindo uma função simbólica que se sobrepõe à função dramática.

Não é o caso, diante do recorte proposto por este trabalho, lidar com os tipos de enquadramento que remetem a outro tipo de emolduração, do gesto fotográfico, apesar deste compor a tipologia dos olhares e das construções dos quadros. Há especificidade na fotografia tirada quando, ao final do filme, Dora e Josué celebram, ao lado da efígie do Padre Cícero, a sua união. A cena se dá depois que ambos conseguem dinheiro com o negócio de escrever cartas "para o Santo", no dia seguinte à mudança definitiva do caráter de Dora.

Por ora, lembremos que a fotografia será exibida exatamente no momento de maior tensão emotiva causada pelos recursos da narração, no final do filme, na cena já lembrada no começo deste escrito, quando o menino e Dora veem, ao mesmo tempo, em espaços disjuntos, a mesma imagem. E choram, é claro. A fotografia do definitivo enlace entre os dois pertence a um universo de reiterações de signos de atestação de presença. Estas táticas de reiteração e condução do relato demandariam outro tipo de análise. Além da fotografia como signo da amizade selada, tivemos, ao longo do filme, o pião como objeto que remete ao pai carpinteiro, o lenço da mãe morta que fora transformado em ex-voto, as cartas como sinais de existência e como objetos portadores de mensagens. 


\section{Fisionomia e narratividade: sobre uma mudança de caráter}

O uso do primeiro plano em Central do Brasil revela o seu duplo objetivo dentro da matriz clássico-narrativa: promover a psicologização de personagens e ser desenvolvimento na narrativa. Através de gestos, feições e olhares, o cinema de Griffith fez um elogio à força do cinema como expressão visual da intimidade, ao mesmo tempo em que há a vivência plena do instante decisivo dramático, questão de desenvolvimento na montagem, construção de ações e reações na linguagem do cinema (Cf. Xavier, 1984). Uma cena, seguindo o princípio básico da "impressão de realidade", é segmentada em visões parciais.

Além de promover a segmentação, o material se dedica à integralização e clareza de pontuações sobre o caráter das personagens. A relação de Dora e Josué caminha, via de regra, num amadurecimento que pontua a "virada" que fará a personagem feminina. Josué é o arauto do caminho que metaforiza o seu próprio caminho: ele só irá encontrar o lugar do pai quando ela, redimida, se lembrar de um pai idolatrado e não o alcoólatra. Falando a respeito das personagens de O Pagador de Promessas (Anselmo Duarte, 1962), mas numa constatação que alcança a linearidade da decupagem clássica em geral, Ismail Xavier afirma:

Acima de tudo é preciso fazê-las psicologicamente inteligíveis, localizar claramente seus dramas, dentro de uma representação que nos coloca as coisas em ordem e nos dá o conforto de sentir, passo a passo, a posse dos dados essenciais para o entendimento de tudo. (Xavier, 1983: 47).

Podemos entrever na análise da narrativa de Central do Brasil diversas maneiras utilizadas para narrar, no intuito de homogeneizar o discurso, assegurando ritmo e provocando as emoções. Todavia, as diversas maneiras obedecem à presença da teleologia do discurso narrativo do cinema industrial, que justifica os vários segmentos de acordo com o seu papel na consumação que dá "sentido" ao precedente, em um desfecho que emoldura a diegese (Cf. Xavier, 1984). Estas "diversas maneiras" se cristalizam em elementos concretos presentes no filme, orientando o espectador na leitura unidimensional do conflito e de suas imprecações. São os índices da família decomposta e que está sendo recomposta, e os índices dos momentos da relação, entre Dora e Josué, que conduz a narrativa. São, também, as reiterações que balizam a diegese com mudanças de clima na narrativa, da tristeza à felicidade e da presença à nostalgia (também no caminho inverso) - os depoimentos em cartas, lembranças dos 
pais das protagonistas, as mudanças de foco de tensão.

Examinemos com mais detalhamento a mais expressiva articulação narrativa emoldurada por imagens pregnantes, uma vez que foram produzidas com claro objetivo de impor uma textura documentária aos rostos e fisionomias escolhidos. Referimo-nos ao começo e ao final do filme, às "cenas-depoimentos" das cartas. É evidente o caráter de começo e final de ciclo que envolve a sucessão de faces diante da escrevedora de cartas. Antes mesmo da apresentação das personagens centrais, vemos uma mulher (Socorro Nobre) que chora copiosamente enquanto dita a sua carta. Outros rostos que se sucedem igualmente reportam situações tristes ou comovedoras. Na finalização do filme, temos o polo oposto: os peregrinos que se dedicam a ditar cartas para o "Santo" estão alegres e reconhecem alguma graça alcançada. Vemos sorrisos e ouvimos boas novas. Algo se passou no miolo do relato que operou uma profunda transformação de tom.

Contudo, a ideia de caminho de movimento intermitente em Central do Brasil, é instaurada como acidental em boa parte do desenvolvimento. A partida de Dora da rodoviária do Rio de Janeiro quase não ocorre após uma briga com Josué. Aparentemente fruto do titubeio da personagem, o suspense na narração é mais uma amostra da "economia" que marca a fabulação que pretende prender a atenção. Logo, os deslocamentos serão sempre marcados claramente em seu leitmotiv andante instaurado desde o começo, e são parcimoniosamente controlados em momentos de suspensão.

Pensemos em outra cena, da tentativa de abandono do menino em pleno sertão, que não se efetiva. Dora deixara a criança no ônibus. Quando se apercebe que o pequeno desceu do ônibus e o dinheiro deixado por ela na bolsa foi perdido, se desespera e se senta num rincão da parada de ônibus, desolada. Constrói-se, então, um comentário através de uma imagem e do som: a visão consecutiva de uma cabra manca, em seu desalinhado deslocamento, no mesmo rincão, instala uma metáfora que comenta a incapacidade da personagem de decidir sobre o seu próprio destino. O plano funciona como um tableau que aparece logo depois de Dora se sentar desolada de ver o ônibus partir com o seu dinheiro. O mesmo tipo de emolduração significativa acontece na cena em que o caminhoneiro César ("Bené”) (Othon Bastos) vai embora. Dora sai maquiada do banheiro e observa através da abertura de uma janela basculante a partida do motorista. A música pontua o desalinho do seu rosto emoldurado pela vidraça. Há abandono e tristeza.

Todavia, o caráter de Dora pode ser alterado e redimido, cumprindo uma trajetória 
rumo à virtude, seguindo uma curva característica do melodrama. Esta alteração se concretiza após a cena de "purgação" do desmaio realizada com a montagem paralela na Casa dos Milagres. Aqui se situa um dos momentos de maior tensão dramática de Central do Brasil, a reviravolta. Novamente, as fisionomias populares estão à serviço de uma textura que remete ao caráter "genuíno" do rosto de personagens que seduzem pela promoção de um conteúdo de autenticidade. Depois de correr no entremeio da multidão de peregrinos, aos gritos, em busca do menino fujão, a velha indigna adentra a Casa dos Milagres. Lá fora, aumenta o calor das orações. São apresentadas faces imbuídas de grande comoção, num jogo da montagem que traz paralelamente o rosto de Dora e seu já penoso deslocamento dentro da casa. O giro dos fogos de artifício e o espocar dos tiros de foguetes estão no ápice da paulatina aceleração até o desmaiar da personagem. O enlevo máximo da reza coincide, através da montagem, com o trabalho de purgação da até então velha indigna.

A tela preta e o longo fade que se seguem promovem o recomeço e o filme não se movimenta muito, pois são representadas somente as ações essenciais para o equilíbrio da trama na sua virada. Já é o dia seguinte. Dora repousa sobre o colo de Josué. A pacificação entre os dois é marcada pela "Piétà inversa" de Walter Salles 5 . A escultura de Michelângelo, que mostra Cristo nos braços de Maria após ser purgado, é mais uma reiteração da virada do caráter de Dora. A música leve complementa a placidez do momento de re-sensibilização da personagem. O arauto termina a sua tarefa; dali em diante as posições se transmutam: ele voltará a ser uma criança sem poder de direcionamento.

A cena do recomeço, que se inicia com Dora no colo de Josué, constitui-se um momento "parado", quando a câmera explora as figuras populares que estão presentes no dia seguinte da festa - um menino cantador, um pastor evangélico, barracas de vendedores. Por iniciativa de Josué, os dois conseguem arranjar algum dinheiro. Os depoimentos que se seguem emoldurarão a narrativa, claro sinal da virada. Houve a pacificação. Voltemos ao cinema do princípio do século XX. Ao abordar dois curtas de Griffith, A Corner in Wheat (1909) e The usurer (1910), Ismail Xavier comenta a composição que reitera e denota a volta ao equilíbrio:

5 Conferir a entrevista de Walter Salles à Revista de Cinema, onde o diretor elabora sobre o projeto de resensibilização do filme e alude à criação, com inversão de papéis, da Pietá (Salles, 1999). 
É recorrente, em Griffith, a composição em tableau para encerrar o filme. Restituído o equilíbrio e afastado o perigo, as pessoas (a família, em geral) aparecem numa composição serena, às vezes jocosa, que celebra a felicidade (em casos raríssimos, a tristeza). O tableau tem, em casos específicos, um rico poder de sugestão quando o final retoma a imagem de abertura, fecha um ciclo e emoldura a estória (Xavier, 1984: 42).

\section{As efígies e os grandes planos gerais}

Até aqui, aludimos às táticas de narração que se compõem com imagens que empregam a luz no filme de modo a mobilizar a função dramática da sua representação. De acordo com a tipologia proposta por Jacques Aumont em seu estudo O Olho interminável, há ainda as funções simbólica e atmosférica no seu modelo de utilização da luz nos filmes (Aumont, 2004: 172-175). Esta divisão de funções é realizada grosso modo, como explica o autor. Não obstante, é útil para compreendermos como a imagem elabora relações com o filme em geral.

A função dramática diz respeito a relações propriamente espaciais e cênicas. Evidentemente, a exposição e ênfase em certas zonas da imagem estão a serviço da produção da diegese. A narração elabora-se, então, através da imagem. A função simbólica "liga a presença da luz na imagem a um sentido", conforme explica o autor (ibidem: 173). Geralmente imanta a representação com algo de extraordinário, em uma criação de agentes transcendentes à narrativa, com algo de sobrenatural, de graça ou de sobre-humano. Já a função atmosférica é a que não responde a codificações simplistas, pois diz respeito a delimitações do quadro ou de zonas do quadro. A incrustração de uma função atmosférica é "fraca", mas leva a efeitos conotativos do quadro como um todo. Seria, segundo o autor, um "logínquo bastardo da função simbólica" (ibidem: 174).

Temos, no filme em questão, a utilização parcimoniosa, mas eloquente da simbologia do culto mariano. Desde a cena em que Josué se vê solitário em uma noite soturna na Central do Brasil, comparecem imagens as mais variadas. A primeira delas é a mais significativa, pois acontece no oratório do local. A estátua de uma santa está envolvida pela aura da luz dourada do fundo e o relato claramente dá a entender que o garoto está lidando com o luto da morte da sua mãe. Há a proposição, pela montagem, de um plano ponto-de-vista do ângulo em contra-mergulho da santa. Na mesma cena em que Josué adentra a casa de Dora e vê na parede um quadro de louça com uma casinha, 
conforme já expusemos, vê também uma virgem com um menino ao colo. Não é o caso de continuar a perfilar as mostrações de quadros de culto mariano. É interessante pontuar, contudo, que as imagens de Jesus são bem menos utilizadas, a exemplo do adesivo colado no vidro do caminhão da carona da dupla de protagonistas.

A principal divisão de espaços em Central do Brasil se dá entre o locus da cidade e a dinâmica do movimento que revela um outro Brasil, do viver interiorano mais genoíno e acolhedor. A grande cidade é representada como espaço extremamente fragmentado. A estação Central do Brasil, no Rio de Janeiro, é lugar de tristeza, abandono, aliciamento e morte. Imagens entrecortadas pelo enorme fluxo de pessoas são combinadas com rostos que indicam pobreza e solidão. Iniciamos o filme justamente com a fala de uma mulher que se comunica por carta com alguém que está preso. Ela diz estar "trancada aqui fora". Em seguida, vemos mais movimento de passageiros através de uma grade na estação. O princípio de fundo da narrativa melodramática, de tudo explicitar, funciona desde os primeiros segundos do relato.

As cartas ditadas na estação Central do Brasil no começo do filme são testemunhos de desalento, desencontro, ressentimento e revolta. A cena da morte de Ana (Sôya Lira), mãe de Josué, é indicativa da relação entre extrema fragmentação na montagem e elaboração deste espaço onde se desfaz o tecido social. $O$ atropelamento da mãe é mostrado com muitos planos, que se sucedem em poucos segundos. Não há acolhimento do menino em prantos pelos anônimos transeuntes que mais se interessam pelo corpo estirado no chão. Josué enfrenta solitário a morte de sua mãe. E mais: haverá apenas os interessados em se valer da sua orfandade para obter vantagens, a exemplo do que se passará com a protagonista Dora, que o venderá a uma quadrilha. A este locus segmentado e convulsivo a narrativa contrapõe o fluxo do movimento que se inicia com a viagem propriamente dita. As imagens ganham nova relação escalar e as sequências que pontuam o trajeto até a casa do pai são intercaladas com a composição de grandes planos gerais. A proposição de imagens com vastos horizontes está serviço do estabelecimento de uma meta, para a manutenção do relato, e da criação de atmosferas, para o deleite do espectador. Além disso, muitas vezes o plano geral com impressão de grande profundidade de campo é inserido dentro de uma cena, rebatendo na paisagem as subjetividades das personagens. Vejamos alguns casos.

Logo na saída se instaura o contínuo seguimento da câmera que acompanha o ônibus no mesmo ritmo de movimentação. É um tipo de imagem em plano geral mais fechado apenas no veículo, proposição que acompanhará também o caminhão da futura 
carona. É fundamental para dar esteio ao olhar de dentro do ônibus no dia seguinte, quando o menino observa os longes do quadro através da janela. Aqui, pela primeira vez, o espectador comparte a visão da personagem. A emolduração com a janela do ônibus traz indicação de uma analogia que marcou a própria invenção do cinema no final do século XIX, quando a janela de um trem emulava o recorte da janela da câmera cinematográfica. Os objetos mais próximos do veículo em movimento atravessam rapidamente o quadro, mas a distante linha do horizonte e a paisagem implicada neste olhar orientam nossa observação. Especialmente no final desta cena há o mais encantador quadro que envolve o movimento lateral do ônibus visto de fora e em direção transversal para o fundo, distanciando-se do ponto de vista da câmera, enquanto o céu e as montanhas ao fundo propõem outro enquadramento dentro do quadro. É um dos momentos que promovem o gozo do nosso olhar: há o azul do céu, há uma réstia de alta chuva no canto superior esquerdo. O ônibus vai tornando-se cada vez menor: faz-se da sua materialidade figura e se elabora uma verdadeira poesia da imagem em franco distanciamento.

A cena na qual Dora vê partir o ônibus com o dinheiro que deixara para Josué é importante por estabelecer uma visada em plano geral implicando a personagem a olhar da paisagem. A linha do horizonte é marcada pelas montanhas ao fundo. Dora está de costas, no primeiro plano da imagem, e o céu acinzentado prepara o desconsolo do quadro da cabra manca, já aludido anteriormente, que virá em seguida. No grande plano geral, céu cinza e solo em imensa profundidade só são interpelados pela leve linha da estrada que leva o ônibus já para bem longe da senhora. Curiosamente, a cena que mostra personagem a observar o longe do quadro no mesmo campo não é utilizada na finalização do filme, pois não vemos Josué e a paisagem integrados, restando apenas o jogo do plano ponto-de-vista do menino que, chorando, vê o ônibus com Dora já bem distante dentro do quadro. É importante anotar que o corte nos leva para dentro do ônibus, promovendo o salto para junto de Dora também em lágrimas. O filme termina justamente com este super salto para dentro de um ponto distante da paisagem.

\section{5. À guisa de uma finalização}

Procuramos examinar a narratividade melodramática com um pensamento que envolve o estudo da imagem e da narração do filme. A ideia era chamar a atenção para 
articulação contraditória de um relato contínuo, retornando a Central do Brasil e analisando-o a partir da leitura dos livros Discurso cinematográfico e por Griffith, estudos do crítico e teórico Ismail Xavier. O objetivo era posicionar um olhar que examina a persistência do cinema de decupagem clássica, mas que também poderia ser investigado em outros ângulos.

A permanência da teleologia redentora é colocada em questão pelo estudo das formas de equacionamento dos sujeitos na narrativa. É, sem dúvida, uma equação problemática e conservadora. O drama da reintegração moral da família é ladeado pela questão do pertencimento, da busca do "mais-próprio". Foi analisado privilegiando o desenrolar da economia narrativa: abertura e fechamento da diegese, procedimentos de decupagem clássica, imaginário da narração, construção dos planos gerais, homogeneização do relato e busca da emoção do espectador.

Segundo o ângulo deste estudo, a narrativa do filme Central do Brasil se estabelece com a construção da homogeneidade visual e na exploração de princípios clássicos de representação, de diegetização do universo representado. Entre deslocamento e suspensão do movimento, remete-se a algo que integra o filme desde os seus planos iniciais: uma dinâmica que pode ser resumida no movimento de chegada ou partida de um trem de passageiros, explorando uma música de andamento cadenciado como o próprio deslocamento pressupõe, com o "andante" que acompanha as personagens por todo o filme. Já os momentos suspensivos delimitam atmosferas, identidades psicológicas e enquadramentos simbólicos em seu jogo de explicitação de caráter e mudança de caráter. Há também a interveniência de uma estratégia de construção dos longes do quadro, num jogo característico de elaboração de distâncias e da linha do horizonte que pontuam determinadas sequências. Assim, através da brilhante articulação entre imagem e narratividade, o melodrama clássico-narrativo se atualiza novamente, com o encantador uso da textura documentária, seguindo a condução do infante desprotegido.

\section{Referências}

AUMONT, Jacques et al. A Estética do Filme. Campinas, SP: Papirus, 1995.

AUMONT, Jacques. O Olho interminável. [Cinema e pintura]. São Paulo: Cosac \& Naify, 2004. CANEVACCI, Massimo. O duplo vínculo da televisão. Revista Veredas. n 35 . Rio de Janeiro, 
Centro Cultural do Banco do Brasil, ano 3, p. 7-8, nov, 1998.

HERMANNS, Ute. A viagem no cinema brasileiro. Cinemais. Rio de Janeiro, nº 6, p. 119-134. jul/ago, 1996.

MOUTINHO, Marcelo. Em busca do tempo da delicadeza. Cinemais. Rio de Janeiro, $\mathrm{n}^{\circ} 21, \mathrm{p}$. 99-114, jan/fev, 2000.

PUDOVKIN, V. Métodos de tratamento do material (montagem estrutural). In: XAVIER, Ismail (org.). A experiência do cinema. $2^{\mathrm{a}}$ ed. rev. e amp. Rio de Janeiro: Edições Graal/ Embrafilme, 1983: 57-65.

SALLES, Walter. Que país é este? In.: Estudos de cinema, São Paulo, nº 2, 1999: 11-29.

VASCONCELOS, Gilberto Felisberto. Estética Ex-FHC. Folha de S. Paulo. São Paulo, 10 fev. 1999.

XAVIER, ISMAIL. $O$ discurso cinematográfico: opacidade e transparência. $4^{\text {a }}$ ed. São Paulo: Paz e Terra, 2008.

Parábolas cristãs no século da imagem. In.: O Olhar e a cena. São Paulo : Cosac \& Naify, 2003: 101-125.

Figuras do ressentimento no cinema brasileiro dos anos 90. In. : RAMOS, Fernão Pessoa e outros (orgs.). Estudos de cinema 2000 - SOCINE. Porto Alegre: Sulina, 2001: 78-98.

O cinema brasileiro dos anos 90. Revista Praga - Estudos marxistas. nº 9, São Paulo, Hucitec, jun 2000: 97-138.

. Griffith. São Paulo: Brasiliense, 1984.

. Sertão mar: Glauber Rocha e a estética da fome. Rio de Janeiro: Brasiliense, 1983. 